\title{
Criteria for social media-based scholarship in health professions education
}

\author{
Jonathan Sherbino, ${ }^{1,2}$ Vineet M Arora, ${ }^{3}$ Elaine Van Melle, ${ }^{1}$ Robert Rogers, ${ }^{4}$ \\ Jason R Frank, ${ }^{1,5}$ Eric S Holmboe ${ }^{6}$
}

${ }^{1}$ Royal College of Physicians and Surgeons of Canada, Ottawa, Canada

${ }^{2}$ Department of Medicine, McMaster University, Hamilton, Canada

${ }^{3}$ Department of Medicine, USA

${ }^{4}$ Department of Emergency Medicine, University of ${ }^{5}$ Department of Emergency Medicine, University of Ottawa, Ottawa, Canada

${ }^{6}$ Accreditation Council for Graduate Medical Education, Chicago, USA

\section{Correspondence to} Dr Jonathan Sherbino, McMaster Clinic, Hamilton General Hospital, 237 Barton St $\mathrm{E}$, Hamilton, Ontario, Canada L8L 2X2;

sherbino@mcmaster.ca

Received 5 February 2015

Revised 25 May 2015

Accepted 23 July 2015

Published Online First

14 August 2015 University of Chicago, Chicago, Kentucky, Lexington, USA

ABSTRACT

Background Social media are increasingly used in health professions education. How can innovations and research that incorporate social media applications be adjudicated as scholarship?

Objective To define the criteria for social media-based scholarship in health professions education.

Method In 2014 the International Conference on Residency Education hosted a consensus conference of health professions educators with expertise in social media. An expert working group drafted consensus statements based on a literature review. Draft consensus statements were posted on an open interactive online platform 2 weeks prior to the conference. In-person and virtual (via Twitter) participants modified, added or deleted draft consensus statements in an iterative fashion during a facilitated $2 \mathrm{~h}$ session. Final consensus statements were unanimously endorsed.

Results A review of the literature demonstrated no existing criteria for social media-based scholarship. The consensus of 52 health professions educators from 20 organisations in four countries defined four key features of social media-based scholarship. It must (1) be original; (2) advance the field of health professions education by building on theory, research or best practice; (3) be archived and disseminated; and (4) provide the health professions education community with the ability to comment on and provide feedback in a transparent fashion that informs wider discussion.

Conclusions Not all social media activities meet the standard of education scholarship. This paper clarifies the criteria, championing social media-based scholarship as a legitimate academic activity in health professions education.

\section{SLinked}

- http://dx.doi.org/10.1136/ postgradmedj-2014-133230 - http://dx.doi.org/10.1136/ postgradmedj-2015-133353 - http://dx.doi.org/10.1136/ postgradmedj-2015-133358 - http://dx.doi.org/10.1136/ postgradmedj-2015-133612 - http://dx.doi.org/10.1136/ postgradmedj-2015-133686

\section{CrossMark}

To cite: Sherbino J, Arora VM, Van Melle $\mathrm{E}$, et al. Postgrad Med J 2015;91:551-555.

\section{INTRODUCTION}

Scholarship is a core competency for clinician educators (ie, clinicians who are able to apply education theory to practice in their role as education consultants). ${ }^{1}$ The current generation of clinician educators has benefited from an evolving understanding of scholarship. Initially, the work of Boyer and Schulman described how teaching could be developed and credited as academic scholarship. ${ }^{2} 3$ Building on this work, education scholarship has been defined as 'an umbrella term, which can encompass both research and innovation in health professions education. Quality in [education scholarship] is attained through work that is: peerreviewed, publicly disseminated and provides a platform that others can build on. ${ }^{4}$ Specifically, it is the inclusion of innovations into this expanded definition of scholarship that has allowed clinician educators to be academically acknowledged for a major portion of their academic activity. Innovations are distinct from the scholarship of discovery (ie, education research) and include the creation, integration and application of education work, such as a novel teaching method or assessment instrument.

The rapid emergence of social media within society has also influenced health professions education. While social media are increasingly adopted by clinician educators as a way to create and disseminate an innovation, substantial questions remain about how these activities are viewed through the traditional lens of scholarship. Thus, the challenge for clinician educators engaged in social media-based innovations is to appropriately evaluate their work as scholarship.

Traditional metrics of the influence of a scholarly innovation include conference presentations and journal publications. Indeed, Glassick provided scholarly standards against which innovations in health professions education were to be judged, including clear goals (ie, an original idea); adequate preparation (ie, building on established work); appropriate methods, significant results (ie, important outcomes), effective presentation (ie, dissemination of the work to the broader community); and reflective critique (ie, evaluation of the innovation). ${ }^{5}$ The development of social media has made possible alternative metrics of influence. Incorporating alternative metrics into traditional understandings of scholarship is important since academic advancement for clinician educators is linked to a promotion process that values the dissemination and adjudication of the influence of innovations.

The purpose of this study was to define the criteria for social media-based scholarship in health professions education using a consensus approach of health professions educators.

\section{METHODS}

\section{Review of the literature}

To inform the draft consensus statements, a review of the literature was performed. A search of the Medline, Embase, ERIC and PsycINFO databases was conducted using the keywords (or keyword variations) of 'scholarship' AND ('social media' or 'social networking') AND ('medical education' or 'health professions education'). A Google Scholar search was also performed using the keywords listed above. The first 500 results (sorted by relevance) were scanned.

Major North American medical conference syllabuses from the last 3 years were scanned to identify speakers on the topic of social media and 
education. The American College of Chest Physicians Meeting, the American Geriatrics Society Annual Meeting, International Conference on Residency Education, the Society for Academic Emergency Medicine Annual Meeting and the Society for General Internal Medicine Annual Meeting all had sessions on the topic. Speakers were contacted directly with a request for published or grey literature on defining or evaluating social media-based scholarship in health professions education.

\section{Development of draft consensus statements}

Recognising the lack of guiding literature specific to social media-based scholarship, an expert working group (the authors) developed draft consensus statements based on themes that were identified in the literature specific to traditional education scholarship. The consensus statements were modified to maintain relevance to social media-based scholarship. The draft consensus statements were posted on an open interactive online platform 2 weeks prior to the consensus conference (the 2014 International Conference on Residency Education's Social Media Summit in Health Professions Education), allowing participants to reflect on and post comments relating to the draft consensus statements in advance of the conference.

\section{Validation of consensus statements}

During a facilitated $2 \mathrm{~h}$ session, in-person and virtual (ie, via Twitter) health professions educators were able to modify, add or delete the draft consensus statements in an iterative fashion until consensus was achieved. A description of the recruitment process of health professions educators is described in the linked companion papers. A moderator facilitated an open unstructured group discussion. Comments and feedback via Twitter were live-streamed on large monitors with a second dedicated in-person curator championing novel concepts and identifying points of agreement or disagreement from the Twitter feed. The consensus process required that all participants endorse the statement before it was considered final. This process meant that discussion would continue until the perspective of every participant was appropriately addressed and incorporated into the final statement. Consensus required an absence of any objection, at times leading to a more general phrasing of an issue so as to ensure broad agreement. A statement was not considered final until consensus was achieved.

This consensus conference did not require research ethics board approval.

\section{RESULTS}

\section{Review of the literature}

No article was identified that provided either a definition or evaluation criteria for social media-based scholarship in health professions education. Three articles were identified that discussed the integration of social media as a form of research, ${ }^{6}$ the role of social media in academic promotion ${ }^{7}$ and the utility of alternative metrics linked to social media. ${ }^{8}$

\section{Participants in the consensus process}

Thirty-two health professions educators participated in person in this portion of the consensus conference and 20 individuals participated virtually in this portion of the consensus conference, producing more than 70000 Twitter impressions. More than 20 education organisations from Canada, the USA, the UK and Oman were represented.

\section{Validated consensus statements}

Table 1 lists the unanimously endorsed statements.
Table 1 Consensus statements on defining and evaluating social media-based scholarship

\begin{tabular}{ll}
\hline Element & Consensus statement \\
\hline Definition & Social media-based scholarship in health professions \\
education must: \\
Bdvance the field of health professions education \\
be archived and disseminated \\
Process \\
community with the ability to comment on and \\
provide feedback in a transparent fashion that \\
informs wider discussion \\
Criteria for authorship should be based on the \\
standards established by the International Committee \\
of Medical Journal Editors \\
Evidence of transparent critical appraisal is required \\
for social media-based scholarship in health \\
professions education \\
Scholarly innovations have the potential to impact \\
the health professions education community and \\
others in a rapid and/or broad fashion \\
While intellectual property must be preserved, \\
scholarly innovations should be made as accessible \\
as possible \\
Indicators, including alternative metrics, should be \\
captured and analysed to demonstrate the \\
dissemination and impact of social media-based \\
scholarship \\
The health professions education community should \\
champion social media-based scholarship as a \\
legitimate academic pursuit
\end{tabular}

\section{DISCUSSION}

The consensus of 52 health professions educators from 20 organisations in four countries defined four key features of social media-based scholarship. It must (1) be original; (2) advance the field of health professions education by building on theory, research or best practice; (3) be archived and disseminated; and (4) provide the health professions education community with the ability to comment on and provide feedback in a transparent fashion that informs wider discussion.

The distinction between social media-based scholarship and traditional education scholarship is that social media-based scholarship directly incorporates social media as a component of the research or innovation. However, digital technology creates new challenges in the adjudication of social media-based scholarship. For example, the digital technology supporting social media makes it easy to reproduce (or minimally alter) and subsequently disseminate ideas developed by others-consider the case of retweets, for example. The requirement of originality, however, ensures that social media-based scholarship does not function simply as an amplifier (eg, collecting the scholarship of others and simply hosting it on a social media platform). Rather, true scholarship requires original work.

One of the unique advantages of social media is the capacity to create an interactive connected social learning experience. This functionality aligns with current educational theories that promote learning through the social construction of knowledge and the participation in communities of practice. ${ }^{9}{ }^{10}$ Audience and author discussion and feedback, embedded within the digital platform, is a standard of scholarship unique to social media. For example, a blog or podcast that fails to engage an audience in shared dialogue would not meet the standard of scholarship. 
Social media offer unique opportunities for broad dissemination and active audience engagement yet the standards for authorship do not change. Specifically, authorship requires:

- conception or design of the innovation; or

- acquisition, analysis or interpretation of content; or

- drafting or critical revision (to add important intellectual content) of the innovation; and

- final approval of the disseminated version of the innovation, including being accountable for the accuracy and integrity of the innovation. ${ }^{11}$

The collaborative nature inherent in social media typically results in multiple authors with varied stages/timing of contribution. Not every contributor to a social media innovation will achieve authorship, in the same manner that not every contributor to a traditional research paper achieves authorship. Acknowledgement of contributors, and not the provision of authorship, is an appropriate mechanism (already common in traditional media) to balance the inherent collaborative nature of social media-based scholarship with the recommended standards of authorship. While digital media has tacitly endorsed anonymous authorship or the use of pseudonyms, social mediabased scholarship requires an authentic identity. An authentic identify ensures that an individual stands behind the innovation, taking both responsibility and credit.

Critical appraisal undergirds the credibility and validity of scholarship. However, traditional (eg, solicited content expert) peer reviewers alone represent only a tiny fraction of the potential end users of the innovation or research. Social media provide a number of different (and novel) dissemination channels, providing an important mechanism to obtain open, transparent and critical appraisal from end users. End users are often better suited to understand the issues around design (ie, layout or optimisation of the technology), application and generalisability. Crowd-sourced critical appraisal (unique to social media-based scholarship) avoids the challenges of incomplete traditional peer review ${ }^{12}$ and promotes large sample 'appraisal saturation' that addresses issues of reliable analysis that plague individual reviewer idiosyncrasies, common to all forms of performance appraisal. ${ }^{13}$

The digital platforms that drive social media allow near simultaneous development and publication of innovations. This lack of a pre-publication pause creates the potential of failed internal pre-publication peer review that is typical of most scholarly work (eg, sharing and refining a concept within a closed group of peers prior to broader distribution to a community). Scholars should be conscious of this issue, which is unique to social media, and take active steps to prevent the unintentional premature release of an innovation that might negatively impact the health professions community (eg, dissemination of incorrect information, incomplete concepts, or misinterpreted results or ideas).

Free open access is a formative principle in social media. The free open access medical education movement (FOAM, also known via the hashtag FOAMed) is bound by the loosely woven philosophy that high-quality medical education resources and interactions can, and should, be free and accessible to all who care for patients and especially those that teach others the art and science of medicine. Importantly, FOAM enthusiasts also encourage the re-use and modification of their resources to suit user requirements and local needs ... the origins of FOAM lie in the Hippocratic Oath itself, which states “... and to teach them this art-if they desire to learn it-without fee and covenant". ${ }^{14}$ Free open access to social media innovations prevents the endless duplication of resources, which has frustrated the effective advance of health professions education. Certainly, there must be an appropriate balance sought between the needs of the health professions education community for ready access to social media innovations and the intellectual property of authors. Creative Commons licences may offer tailored solutions to this challenge, providing different levels of copyright permissions for intellectual property. ${ }^{15}$

Valuable scholarship has impact. Publishing in print journals has been the traditional metric for determining impact, influencing advancement and promotion in academic environments. Social media-based scholarship changes the traditional model by introducing new channels of dissemination and alternative metrics of impact. One approach to measuring impact is the RE-AIM framework-Reach, Effectiveness, Adoption, Implementation and Maintenance. ${ }^{16}$ Table 2 includes specific alternative metrics relating to the reach of social media-based scholarship. Effectiveness looks at the influence of an innovation

Table 2 Common alternative metrics of the reach of social media-based scholarship

\begin{tabular}{|c|c|c|}
\hline Source & Metric & Metric definition \\
\hline \multirow[t]{5}{*}{ Google Analytics } & Page views & Number of times a webpage was viewed \\
\hline & Users & $\begin{array}{l}\text { Number of times users from different Internet Protocol (IP) addresses viewed a site (previously termed } \\
\text { 'unique visitors' by Google) }\end{array}$ \\
\hline & Number of cities & Number of unique jurisdictions by city (as registered by Google Analytics) who viewed a site \\
\hline & Number of countries & Number of unique jurisdictions by country (as registered by Google Analytics) who viewed a site \\
\hline & Average time on page & Average amount of time spent by a viewer on a webpage \\
\hline \multirow[t]{4}{*}{ Blog } & Number of tweets from post & Number of unique 140-character notifications sent directly from the blog post via Twitter to raise awareness of a post \\
\hline & Number of Facebook likes & Number of times viewers 'liked' a post via Facebook \\
\hline & Number of Google+ shares & Number of times viewers shared a post via Google+ \\
\hline & $\begin{array}{l}\text { Number of site comments } \\
\text { Average word count per blog } \\
\text { comment }\end{array}$ & Comments made directly on the blog in the comments section \\
\hline \multirow[t]{3}{*}{ Symplur Analytics } & Number of tweets & Number of tweets linked to a specific (hashtag) topic \\
\hline & $\begin{array}{l}\text { Number of Twitter } \\
\text { participants }\end{array}$ & Number of unique Twitter participants linked to a specific (hashtag) topic \\
\hline & Twitter impressions & $\begin{array}{l}\text { Number of potential views of tweets linked to a specific (hashtag) topic that appear in users' Twitter streams, as } \\
\text { calculated by number of tweets per user and multiplying it with the number of followers of that user has }\end{array}$ \\
\hline \multirow[t]{2}{*}{ YouTube Analytics } & Number of views & Number of views of a video \\
\hline & Average duration of viewing & Average length of time the video was played with each viewing \\
\hline
\end{tabular}


on the practice of an individual. For example, does a blog devoted to theories of teaching increase clinician educators' knowledge of the topic? Adoption looks at support within a community to use an innovation, including the representation of uptake among individuals and environments-for example, what are the demographics of clinician educators who use the blog? Implementation looks at the fidelity and consistency of delivery of the innovation-for example, how appropriately and regularly were the interactive features of the blog used? Finally, maintenance examines the routine practices that institutionalise and support the use of an innovation-for example, was the blog updated and were new users accessing the blog after the initial launch? Not all elements of the RE-AIM framework must be present to demonstrate impact, but increasing representation argues for increasing influence of an innovation. Of course, the real challenge is with incorporating alternative (new) metrics into a traditional academic advancement and promotion cycle.

Acknowledging the emerging influence of social media on the delivery of health professions education, it will be essential that scholars be identified, mentored and provided with infrastructure and support. ${ }^{17}$ Supporting and rewarding education innovations is not without precedence, with one large research university developing a unique path for academic promotion based on creative professional activities. ${ }^{18}$ Championing social media-based scholarship will ensure the discovery, creation, integration and application of social media innovations that will advance health professions education. ${ }^{19}$

The findings of this study are limited by the self-selected nature of the health professions educators participating in the consensus process. Appropriate representation of the spectrum of health professions education may not have been represented. However, the consensus process required unanimous agreement for each statement to be adopted, thus such criteria may guard against idiosyncratic recommendations.

Not all social media activities meet the standard of scholarship. Rather, this work clarifies the criteria of education scholarship, specific to social media, that build on previous definitions. ${ }^{45}$ Future work should address the role of feedback and critical appraisal in social media-based scholarship. Specifically, if social media-based scholarship requires audience feedback, when is an innovation complete? Moreover, how must authors acknowledge and respond to critical appraisal about their innovation? The interactive rapid response functions of digital platforms have the potential to transform crowdsourced review into a never-ending iterative process. Future work should determine the appropriate point to truncate this process and the appropriate process to acknowledge contributors who modify and transform the initial version of a social media-based innovation.

\section{Main messages}

- Social media-based scholarship includes innovations. It is original, builds on theory and must be archived and widely disseminated.

- Social media-based scholarship requires a digital platform to allow feedback from the education community.

- Not all social media activities meet the standards of scholarship.

- Social media-based scholarship is a legitimate academic pursuit.

\section{Current research questions}

- If social media-based scholarship requires crowd-sourced feedback, when in this cycle is an innovation complete?

- How must authors acknowledge and respond to feedback on their innovation?

- Does crowd-sourced critical appraisal require the inclusion of reviews from content experts?

\section{Key references}

- Van Melle E, Lockyer J, Curran V, et al. Toward a common understanding: supporting and promoting education scholarship for medical school faculty. Med Educ 2014;48:1190-200.

- Glassick CE. Boyer's expanded definitions of scholarship, the standards for assessing scholarship, and the elusiveness of the scholarship of teaching. Acad Med 2000;75:877-80.

- Steinert Y, Snell L. Educational innovation and scholarship: from curriculum design to implementation. In: Sherbino J, Frank J, eds. Educational design: a CanMEDS guide for the health professions. Ottawa; Royal College of Physicians \& Surgeons of Canada, 2011:81-6.

Acknowledgements The authors wish to acknowledge the participants in the consensus conference for their contributions to developing the consensus statements.

Contributors All of the authors contributed to the design and analysis of the results of the project. All authors approved and are accountable for the final version of the manuscript.

Competing interests None declared.

Provenance and peer review Commissioned; externally peer reviewed.

\section{REFERENCES}

1 Sherbino J, Frank JR, Snell L. Defining the key roles and competencies of the clinician-educator of the 21 st century: a national mixed-methods study. Acad Med 2014:89:783-9.

2 Boyer EL. Scholarship reconsidered: priorities for the professoriate. Princeton, NJ: The Carnegie Foundation for the Advancement of Teaching, 1990.

3 Shulman L. The scholarship of teaching. Change 1999;31:11.

4 Van Melle E, Lockyer J, Curran V, et al. Toward a common understanding: supporting and promoting education scholarship for medical school faculty. Med Educ. 2014;48:1190-200.

5 Glassick CE. Boyer's expanded definitions of scholarship, the standards for assessing scholarship, and the elusiveness of the scholarship of teaching. Acad Med 2000;75:877-80.

6 Powell D, Jacob C, Chapman B. Using blogs and new media in academic practice: potential roles in research, teaching, learning and extension. Innov Higher Educ 2012;37:271-82

7 Gruzd A, Staves K, Wilk A. Tensure and promotion in the age of online social media. Proc Am Soc Info Sci Tech 2011:48:1-9.

8 Thelwall $\mathrm{M}$, Haustein $\mathrm{S}$, Larivière $\mathrm{V}$, et al. Do altmetrics work? Twitter and ten other social web services. PLOS ONE 2013;8:e64841.

9 Lave J, Wenger E. Situated learning: legitimate peripheral participation. Cambridge, UK: Cambridge University Press, 1991.

10 Vygotsky L, Mind in Society. The development of higher psychological processes. Cambridge, MA: Harvard University Press, 1980.

11 International Committee of Medical Journal Editors. http:/www.icmje.org/ recommendations/browse/roles-and-responsibilities/defining-the-role-of-authorsand-contributors.html (accessed Jan 2015).

12 Bohannon J. Who's afraid of peer review? Science 2013;342:60-5.

13 Gingerich $A$, Kogan J, Yeates $P$, et al. Seeing the 'black box' differently: assessor cognition from three research perspectives. Med Educ 2014;48:1055-68. 
14 Nickson C, Cadogan M. Free Open Access Medical education (FOAM) for the emergency physician. Emerg Med Australas 2014;26:76-83.

15 Creative Commons. http://creativecommons.org/licenses/ (accessed Jan 2015).

16 Glasgow R, Vogt $\mathrm{T}$, Boles $\mathrm{S}$. Evaluating the public health impact of health promotion interventions: the RE-AIM framework. Am J Public Health 1999;89:1322-7.

17 Bandiera G, Leblanc C, Regehr G, et al. Education scholarship in emergency medicine part 2: supporting and developing scholars. CJEM 2014;16(Suppl 1): S6-S12.
18 Levinson W, Rothman Al, Phillipson E. Creative professional activity: an additional platform for promotion of faculty. Acad Med 81:568-70.

19 Steinert $Y$, Snell L. Educational innovation and scholarship: from curriculum design to implementation. In: Sherbino J, Frank J, eds. Educational design: a CanMEDS guide for the health professions. Ottawa; Royal College of Physicians \& Surgeons of Canada, 2011:81-6.

20 Lin $M$, Sherbino J. A virtual medical education journal club: creating a community of practice using multiple social media strategies. J Grad Med Educ 2015, in press. 